\title{
Simulation on sensory impairment in older adults: nursing education
}

Leah Macaden, Annetta Smith and Suzanne Croy

This document is the Accepted Manuscript version of a Published Work that appeared in final form in British Journal of Nursing, copyright (C) MA Healthcare, after peer review and technical editing by the publisher. To access the final edited and published work see https://doi.org/10.12968/bjon.2017.26.19.1057 


\section{Simulation on sensory impairment in older adults: \\ nursing education}

1. Leah Macaden ${ }^{1 *} \mathrm{RN}, \mathrm{RM}, \mathrm{PhD}$

Lecturer \& Senior Fellow of the UK Higher Education Academy

Email: leah.macaden@uhi.ac.uk

2. Annetta Smith ${ }^{2} \mathrm{RN}, \mathrm{PhD}$

Senior Lecturer \& Head of Nursing

Email: annetta.smith@uhi.ac.uk

3. Suzanne Croy $^{3}$ RMN, MSc Dementia Studies

Lecturer

Email: $\underline{\text { s.croy@abertay.ac.uk }}$

Authors' Affiliations

${ }^{1}$ Department of Nursing, School of Health, Social Care \& Life Sciences, University of the Highlands \& Islands, Scotland, UK

${ }^{2}$ Department of Nursing, School of Health, Social Care \& Life Sciences, University of the Highlands \& Islands, Scotland, UK

${ }^{3}$ Division of Mental Health Nursing and Counselling, School of Social and Health

Sciences, Abertay University, Scotland, UK

* Corresponding Author

Lecturer, Department of Nursing, University of the Highlands \& Islands, Centre for Health Science, Old Perth Road, Inverness, IV2 3JH.

Email: leah.macaden@uhi.ac.uk_Ｔel: 00441463279820 


\section{Introduction}

Sensory impairments are identified as one of the most common chronic and disabling conditions of later life that can impact significantly on quality of life and safety in older adults and their ability to carry out activities of living (World Health Organisation. 2015a)

(World Health Organisation. 2014). Hearing loss disorders are projected to be among the top 10 causes of burden of disease in high and middle-income countries (World Health Organisation. 2015b); agerelated visual impairments and cataracts are projected to move up three or more places in the WHO disease burden rankings (World Health Organisation. 2017) (Mathers, Loncar 2006). Dual sensory loss, which is concurrent loss of both vision and hearing, affects $\mathbf{2 1 . 9}-\mathbf{2 2 . 5 \%}$ of older adults (Brennan, Su \& Horowitz 2006); (Harada etal 2008). In the UK, currently there are approximately 250,000 people with both hearing and vision loss most of whom are over the age of 70 and the number of older adults with hearing loss is estimated to rise to 15.6 million people by 2035 (that is one in five people) (Action on Hearing Loss. 2014). Given the strong association between sensory impairment, older age and the global demographic transition, the prevalence of sensory impairment is expected to rise. This epidemiology has significant implications for both planning and delivery of health and social care services for older adults globally and nationally. 


\section{Background}

Population demographic transition and age related sensory impairments are both significant health care issues and it is therefore pertinent that nurses, health and social care professionals are knowledgeable and confident to care for older adults with sensory impairments. Yet, health care professionals inclusive of nurses often have a very limited understanding of the psychosocial consequences of a dual sensory impairment (Pacala, Boult et al. 2006)

(Bodsworth 2014). As nurses will frequently assess, plan, implement and evaluate care for older adults with sensory impairments, it is important that they possess the knowledge and skills to carry out informed and empathetic care.

Age related sensory loss and its profound impact on the older adult seem to neither feature in the curriculum of health professionals whilst training or in professional continuing education programmes. There is a dearth of reported evidence on the development of education interventions that are tailored around sensory impairments specifically (Pacala, Boult et al. 2006). One of the most resourceful ways to address any health care challenge is through education to build capability and confidence amongst future practitioners (Macaden 2016).

Nursing education must therefore be fit for purpose, relevant to health and social care needs and the demographic transitions that are now universal. This poses a need for nurse educators to be creative and resourceful in their design of pedagogy for the delivery of nurse education that is not only inclusive of social, constructive and experiential aspects of learning but one that is also clinically relevant in order to develop a knowledgeable and skilled nursing workforce. The use of simulation as an effective pedagogical method for the clinical 
component of nurse education has been endorsed by educators and students (Cant, Cooper 2010); (Kelly, Berragan et al. 2016).

Simulation is an instructional process that substitutes real patient encounters with artificial models, live actors or virtual reality patients giving students the opportunity to be able to practice relevant educational principles and self-reflection (Gaba 2004), (Okuda, Quinones 2008).

Following a review on students' fitness for practice at the point of registration in the United Kingdom (UK), the Nursing and Midwifery Council (Nursing and Midwifery Council. 2005) launched a pilot on simulation and practice learning for pre - registration nursing programmes across 13 universities in the UK. Outcomes from this pilot, recommended that simulation in a controlled environment to teach clinical skills can be valuable in addition to clinical experience (Nursing and Midwifery Council 2007). Simulation whilst facilitating learning through the creation of "microworlds "of reality (Wilford, Doyle 2006) also enables students to improve their professional confidence (Pike, O'Donnell 2010) and refine their interpersonal communication skills (Pearson, Mc Lafferty 2011) in a well-supported and nonthreatening environment. Simulation activities can be delivered either as process or action activities (Schiavenato 2009).

Simulation through action is aimed at acquiring competence with specific clinical skills such as a venipuncture or a cardio pulmonary resuscitation that is learnt using a simulator and has outcomes such as manual dexterity and procedural efficiency that are measurable

(Schiavenato 2009). Process activities using simulation are most commonly used to teach critical thinking concepts (Ricketts, Merriman et al. 2012), such as interpersonal communication and other abstract concepts such as empathy, patience, and compassion. 
Simulation also provides the scope to integrate knowledge, clinical skills, relevant skills in assessment and critical thinking in real time, clinical situation (Prion, 2008) and develop reflective practitioners (Murray et al, 2008 ).

Simulation as a pedagogical method has been well researched especially within the education and training of health care professionals as an interesting, interactive and useful learning method (Pearson, Mc Lafferty 2011) with positive association and student satisfaction

(Foronda, Liu \& Bauman 2013). Effective simulations enable nursing students to understand and anticipate what is likely to be expected of them in "real life" situations and influence their practice long term (Kelly, Hager et al. 2014).

\section{Theoretical Framework}

The theoretical underpinnings of simulation are largely grounded in Kolb's theory on experiential learning (Kolb 1984) and Tanner's model of clinical judgement (Tanner 2006) which proposes noticing, interpreting, responding and reflecting as skills that are integral to any simulated activity. Additionally, simulation activity that integrates feedback and guided reflection forges the theory practice link, promotes insight and better synthesis of knowledge on the subject (Bruce, Bridges et al. 2003). This simulation resource was based on Kolb's

(1984) theory on experiential learning to sensitize nursing students at an early stage in their programme on sensory and impairment/s in older adults, and Tanner's (2006) model of clinical judgement incorporating reflection as a key component of student learning. 


\section{Design of the simulation resource}

The literature on the use of simulation as a pedagogical approach to teach sensory impairments is limited despite simulation perceived to be an appropriate experiential learning strategy (Prion 2008) that could facilitate nursing students to experience first-hand, some of effects of sensory impairments whilst helping them do develop empathetic insight into the challenges associated with these conditions. Furthermore, it would be reasonable to assume that such insight would increase student nurses' skills and confidence in caring for older adults with these impairments in practice. The authors developed a simulation based teaching resource which recreated a number sensory challenges that aimed to provide adult and mental health student nurses with opportunities for experiential learning on sensory impairment/s in older adults.

The aims of the simulation were:

1. To create opportunities for students' experiential learning on sensory impairments in older adults.

2. To enable students to gain new insights on sensory impairment/s in older adults.

3. To enable students to appreciate the day to day challenges faced by older adults with sensory impairments.

Six learning stations with each station having a clearly outlined activity involving at least two or more sensory impairments created 'microworlds' (Wilford, Doyle 2006) for students to experience a combination of either visual, hearing, taste, smell or peripheral sensory impairments (Table 1). The learning stations simulated common changes in sensory perceptions associated with the aging process (Schiffman 2007) that tend to be exacerbated 
during critical illnesses or medications (Schiffman and Zervakis 2002), which students are particularly likely to encounter whilst caring for older adults in acute care settings.

Insert Table 1.

\section{Delivery of the simulation}

In total, 125 nursing students, (119 Female and 6 Male students) in their first semester (Year 1) participated in the simulation prior to their first practice learning placement. The nursing students were studying either for the Adult nursing Field ( $n=98)$ or Mental Health nursing Field ( $n=27)$. Each session ran for 90 minutes with 24 students in groups of four, rotating simultaneously around the six stations. Facilitators (Academic staff) ensured that students were supported both with activities and were alert to students who may have indicated anxiety, vulnerability or became overwhelmed with the experience (Nielsen and Harder 2013)

A 10 minute briefing (Rudolph, Raemer, and Simon 2014 ) prior to the simulation involved discussion of the learning outcomes, description of each station and the option for students to speak to the facilitator if they found any station particularly difficult or overwhelming. The students then spent around 10 minutes (6 minutes for the activity and 4 minutes to reflect) at each station. In each group, two students assumed either the role of the older adult (participant) with the impairment or the role of a nurse/ observer. The students were encouraged to change roles as appropriate at each station to gain both experiences. The observer's role was to read out the instructions to the participant at each station and capture the participant's reflections on the thoughts, feelings, emotions and insights that they experienced during the activity (Table 2). 
The classroom environments were adapted to recreate the noise and light levels that are often found in an institution type setting. For example, controllable / dimmable lights were used to modify the amount of light available and constant background noise including people talking and music, mimicked the normal environment that older adults often have to negotiate, particularly in a care home or hospital setting. These additional sensory challenges were created to highlight the difficulties of working in dim light and issues relating to visual / aural sensory overload that older adults with sensory and cognitive impairments may need to negotiate in their care environments (Brush, Meehan, and Calkins 2002).

The final 20 minutes of the session was allocated for debrief that involved facilitated discussions around the recorded reflections for each station particularly focusing around the emotions experienced and insights gained on the sensory impairments experienced by student nurses and their relevance to nursing practice. Debriefing is considered an important stage of simulation (Parker and Myrick, 2010) that reinforces and helps consolidate learning (Yeun, Bang et al. 2014) and student nurses were supported by the facilitators to explore and discuss the thoughts, feelings and emotions that they experienced. For example, student nurses discussed the relevance of colour contrast between fabric and buttons after having participated in station one. The activity at station six also highlighted the importance of informed consent when older adults complete registration / application forms and the potential vulnerability that activity exposed when students signed forms without good understanding of the content. Thus, debriefing allowed student nurses to not only to reflect on their practice from any previous care experience but insights that were relevant in day to day situations (Sinclair, Ferguson 2009)

Feedback during debrief also demonstrated how student nurses without previous care experience were able to communicate their understanding of the complexities and challenges with activities of daily living for older adults with sensory impairment/s. 


\section{Students' Reflections on Simulation Activities}

The range of emotions and feelings that the students reported through reflection following participation in the simulation is illustrated in Figure 1. These emotions were not always directly attributable to any one station but were more generally expressed across the activities at all six stations.

Insert Fig 1

Figure 2 illustrates students' reported benefits of participation in the simulation and the impact on their learning. First, enhanced knowledge and understanding on the impact of sensory impairments, was identified including the vital role of senses to execute daily tasks. Students reported that they found stations 1, 3 and 4 (Table 1) to be the most challenging and complex to negotiate but helped to develop an appreciation of the difficulties older adults with sensory impairments experience performing ordinary daily tasks which are often taken for granted. Second, new insights into the challenges of living with sensory impairment in older adults and experience of the associated frustration and vulnerability was highlighted. Third, students articulated awareness of the need for empathy, good communication, compassion, caring and respectful attitude, and patience in caring for older adults with these impairments. The relevance of these professional values to nursing practice was explored during the debrief, and reflect students' appreciation of a person centered approach to care (Broderick, Coffey 2013).

Insert Fig 2

\section{Discussion}

The aim of simulation was: 'to replicate some or nearly all of the essential aspects of a sensory impairment so that these situations may be more readily understood and managed 
when it occurs for real in clinical practice' (Hovancsek 2007). Previous findings show that simulationbased medical education (SBME) is a powerful intervention to increase learner competence with transferrable skills to improve patient care (McGaghie, Draycott et al. 2011)

The sensory simulation resource was aimed at creating opportunities for students' experiential learning on sensory impairment/s in older adults, to enable them to gain new insights of the daily challenges older adults with these impairments encounter with routine tasks and activities of daily living. Significantly, for older adults with a sensory impairment/s, hospitals and care environments can be challenging places to negotiate, and the added complexities of memory and communication deficits Brush, Meehan, and Calkins 2002) can compromise the effective and safe delivery of nursing care. These challenges are particularly salient if nurses and other healthcare professionals are unaware of the impact of such deficits on their patients (Aulagnier et al, 2005), (Shakespeare, and Kleine 2013).

Simulation that incorporates the affective (emotional) component of learning can be effective (Kneebone 2005) provided the experience replicates real clinical encounters to the best extent possible. Students who participated in this simulation identified a range of emotions and feelings (Fig1), many of them negative as a result of the frustration experienced when participating in the activities while being visually, hearing impaired. Students with previous experience in care settings also reflected that the emotions they experienced helped them to improve their insights to better understand (Fig 2) and relate to some of the emotional responses of some older adults in their care retrospectively. They were able to apply new learning to previous care experiences leading to renewed understanding of the emotions and behaviour of older adults witnessed in previous practice (Liaw 2011). They also discussed that their approach to caring for the resident would be very different with the new insights gained through this experiential learning. It is therefore possible that the affective emotions and 
feelings derived from this simulated learning will probably resurface as triggers or prompts when similar situations are encountered in practice.

Simulation is a teaching method that allows multiple learning objectives to be taught in an environment without risking patient harm. Designing and delivering this simulation has reinforced that being creative whilst designing pedagogical resources for nurse education can stimulate critical thinking, reflective practice and instill confidence (National League for Nursing. 2003). Four critical elements for effective learning were employed in this simulation activity. These elements included, a prebriefing session that clearly outlined the purpose of the simulation activity with the intended learning outcomes, a well-equipped and resourced simulated environment to practice, time built in for reflection followed by an interactive discussion and debriefing. Reflection and debriefing were critical elements of this simulation activity as provision was made for students to explore their feelings associated with the impairments that they encountered, the impact on patients and possible solutions for practice (Neill and Wotton 2011).

The value of debriefing, reflection and guidance from academic facilitators were ranked as the three highly valued components of a simulation on clinical judgment by student nurses (Kelly, Hager et al. 2014). As students were in the early stages of their nursing programme, encouraging them to be reflective from early on in their practice is an essential professional attribute (Tanner 2006). The lasting impact of participation in simulation can be more effective since simulation as a pedagogical approach seems to trigger reflection not just whilst students participate in the simulation but beyond (Kelly, Hager et al. 2014). This prolonged impact is an important factor for nursing students as it is highly probable they will 
care for older adults with sensory impairments throughout their programme and a variety of care settings.

This simulation was a relatively simple, low tech intervention creatively designed to maximize the opportunity for experiential learning on sensory impairments in older adults. Students' reflections and feedback illustrate that they not only gained knowledge and insights into the complex phenomena of sensory impairments in older adults but were also able to appreciate the emotions that older adults with these associated disabilities experienced

(Figures 1 and 2). This was an important outcome as attitudes of nursing staff toward older adults influence the quality of care provided in long term care facilities (Alfarah, Schünemann et al. 2010). Students also reflected that this experiential learning enabled them to develop for example, communication skills and team work (Stirling, Smith et al. 2012) (particularly when they interacted at the stations, took turns at being either the participant / observer and reflected in groups of four at each station) that were transferrable across a range of situations in nursing practice beyond this particular simulation context.

\section{Implications for practice}

This sensory simulation activity, including the reflection and debrief has supported students' ability to develop knowledge and insight on the impact of sensory impairment/s and the additional vulnerability experienced by some older adults. Exposure to simulation has significant clinical relevance as students care for older adults with these impairments. Understanding what may be required of them in the practice setting and anticipating what is likely to happen in real patient situations is highly valued by both students and newly qualified nurses (Kelly, Hager et al. 2014). Therefore, the knowledge and insights gained through this simulated activity have the potential for transferability across a range of real 
clinical situations to influence nurses' attitudes and behaviours and the quality of care provided to various patient groups with sensory impairment/s.

\section{Limitations}

Student reflections discussed in this paper are anecdotal that were captured during reflection and debrief as part of the simulation. The paper primarily focusses on the design and delivery of simulation on sensory impairment in older adults and is therefore descriptive rather than evaluative in its approach. However, a systematic and prospective evaluation of this simulation as a pedagogical approach within pre-registration nurse education is currently in progress.

\section{Conclusion}

Although endorsed in the nursing curricula (Nursing and Midwifery Council 2007), the sustained effectiveness of simulation has not been widely evaluated and in particular simulation around sensory impairment/s. This simulation has helped students o appreciate the complexity of helping to support patients with sensory impairments. Further research s required to explore the longer term impact, if any, of this simulated activity. Nurses will, with increasing frequency encounter older adults with sensory impairment/s in all care settings. Hence teaching strategies that can effectively prepare nurses early on in their careers to appreciate the impact and disability experienced through sensory impairment/s is important. As this vulnerable population of older adults in increasing, nurses need to be able to assess and manage risk as well as provide empathetic and person centered care to older adults.

\section{References}

1. ACTION ON HEARING LOSS. 2014. Hearing Matters. London: Action on Hearing Loss.

2. ALFARAH, Z., SCHÜNEMANN, H.J. and AKL, E.A., 2010. Research article Educational games in geriatric medicine education: a systematic review. BMC Geriatrics, 10(19), pp. 1-5. 
3. AULAGNIER, M., VERGER, P., RAVAUD, J.F., SOUVILLE, M., LUSSAULT, P.Y., GARNIER, J.P. and PARAPONARIS A., 2005. General practitioners' attitudes towards patients with disabilities: The need for training and support. Disability and rehabilitation, 27(22), pp. 1343-1352.

4. BODSWORTH, S.M., 2014. Deaf blindness and mental health. Psychological distress and unmet need among adults with dual sensory impairment. British Journal of Visual Impairment, 29(1), pp. 6-26.

5. BRENNAN, M., SU, Y.P. AND HOROWITZ, A., 2006. Longitudinal associations between dual sensory impairment and everyday competence among older adults. Journal of rehabilitation research and development, 43(6), p. 777.

6. BRODERICK, M.C. and COFFEY, A., 2013. Person-centred care in nursing documentation. International Journal of Older People Nursing, 8(4), pp. 309-318.

7. BRUCE, S., BRIDGES, E.J. and HOLCOMB, J.B., 2003. Preparing to respond: Joint Trauma Training Center and USAF Nursing Warskills Simulation Laboratory. Critical Care Nursing Clinics of North America, 15(2), pp. 149-162.

8. BRUSH, J.A., MEEHAN, R.A. AND CALKINS, M.P., 2002. Using the environment to improve intake for people with dementia. Alzheimer's Care Today, 3(4), pp. 330-338.

9. CANT, R.P. and COOPER, S.J., 2010. Simulation-based learning in nurse education: systematic review. Journal of advanced nursing, 66(1), pp. 3-15.

10. DOTCHIN, C.L., PADDICK, S.M., GRAY, W.K., KISOLI, A., OREGA, G., LONGDON, A.R., CHAOTE, P., DEWHURST, F., DEWHURST, M. and WALKER, R.W., 2015. The association between disability and cognitive impairment in an elderly Tanzanian population. Journal of Epidemiology and Global Health, 5(1), pp. 57-64.

11. FORONDA, C., LIU, S. AND BAUMAN, E.B., 2013. Evaluation of simulation in undergraduate nurse education: An integrative review. Clinical Simulation in Nursing, 9(10), pp. e409-e416.

12. GABA, D.M., 2004. The future vision of simulation in healthcare. Qual Saf health Care, 13(Suppl 1), pp. i2i10

13. HARADA, S., NISHIWAKI, Y., MICHIKAWA, T., KIKUCHI, Y., IWASAWA, S., NAKANO, M., ISHIGAMI, A., SAITO, H. AND TAKEBAYASHI, T., 2008. Gender difference in the relationships between vision and hearing impairments and negative well-being. Preventive medicine, 47(4), pp.433-437.

14. HOVANCSEK, M., 2007. Using simulation in nurse education. In: P.E. JEFFRIES R., ed, Simulation in Nursing Education; from Conceptualization to Evaluation. National League for Nursing, New York. pp. 1-9.

15. KELLY, M.A., BERRAGAN, E., HUSEBO, S.E. and ORR, F., 2016. Simulation in nursing education International perspectives and contemporary scope of practice. Journal of Nursing Scholarship, 48(3), pp. 312-321.

16. KELLY, M.A., HAGER, P. and GALLAGHER, R., 2014. Kelly, M. A., Hager, P., \& Gallagher, R. (2014). What matters most? Students' rankings of simulation components which contribute to clinical judgement. Journal of Nursing Education, 53(2), 97-101. What matters most? Students' rankings of simulation components which contribute to clinical judgement. Journal of Nursing Education, 53(2), pp. 97-101.

17. KNEEBONE, R., 2005. Evaluating clinical simulations for learning procedural skills: a theory-based approach. Academic Medicine, 80(6), pp. 549. 
18. KOLB, D.A., 1984. Experiential Learning: Experience as the Source of Learning and Development New Jersey: Englewood Cliffs Prentice Hall.

19. LIAW, S.K., 2011. Integration of simulation-based learning in the nursing programme: a reflection. Singapore Nursing Journal, 38(4), pp. 28-31.

20. MACADEN, L., 2016. Being Dementia Smart (BDS): A Dementia Nurse Education Journey in Scotland. International Journal of Nursing Education Scholarship. 13(1), pp. 45-53.

21. MATHERS, C.D. and LONCAR, D., 2006. Projections of global mortality and burden of disease from 2002 to 2030. PLoS med, 3(11), pp. e442.

22. MCGAGHIE, W.C., DRAYCOTT, T.J., DUNN, W.F., LOPEZ, C.M. and STEFANIDIS, D., 2011. Evaluating the impact of simulation on translational patient outcomes. Simulation in healthcare: journal of the Society for Simulation in Healthcare, 6 Suppl, pp. S42-7.

23. MURRAY, C., GRANT, M.J., HOWARTH, M.L. and LEIGH, J., 2008. The use of simulation as a teaching and learning approach to support practice learning. Nurse Education in Practice, 8(1), pp.5-8.

24. NATIONAL LEAGUE FOR NURSING., 2003-last update, Innovation in Nursing Education: A call to reform. Available: http://www.nln.org/docs/default-source/about/archived-position-statements/innovation-innursing-education-a-call-to-reform-pdf.

25. NEILL, M.A. AND WOTTON, K., 2011. High-fidelity simulation debriefing in nursing education: $A$ literature review. Clinical Simulation in Nursing, 7(5), pp.e161-e168.

26. NIELSEN, B. AND HARDER, N., 2013. Causes of student anxiety during simulation: What the literature says. Clinical Simulation in Nursing, 9(11), pp. e507-e512.

27. NURSING AND MIDWIFERY COUNCIL, 2007. Simulation and Practice Learning Project. London: NMC.

28. NURSING AND MIDWIFERY COUNCIL. 2005. Consultation on proposals arising from a review of fitness for practice at the point of registration. NMC Circular 31/2005. London: NMC.

29. OKUDA Y., \& QUINONES, J. (2008). The use of simulation in the education of emergency care providers for cardiac emergencies. International Journal of Emergency Medicine, 1(2), pp. 73-77.

30. PACALA, J.T., BOULT, C. and HEPBURN, K., 2006. Ten years' experience conducting the aging game workshop: Was it worth it? Journal of the American Geriatrics Society, 54(1), pp. 144-149.

31. PEARSON, E. and MC LAFFERTY, I., 2011. The use of simulation as a learning approach to nontechnical skills awareness in final year nurse students. Nurse Educ. Pract., 11(6), pp. 399-405

32. PIKE, T. and O'DONNELL, V., 2010. The impact of clinical simulation on learner self-efficacy in preregistration nursing education. Nurse Educ. Today, 30(5), pp. 405-410.

33. PRION, S. (2008). A practical framework for evaluating the impact of clinical simulation experiences in pre-licensure nursing education. Clinical Simulation in Nursing, 4(3), pp. e69- 78.

34. RICKETTS, B., MERRIMAN, C. and STAYT, L., 2012. Simulated practice learning in a preregistration programme. British Journal of Nursing, 21(7), pp. 435-440.

35. RUDOLPH, J.W., RAEMER, D.B. AND SIMON, R., 2014. Establishing a safe container for learning in simulation: the role of the presimulation briefing. Simulation in Healthcare, 9(6), pp.339-349.

36. SHAKESPEARE, T., \& KLEINE, I. (2013). Educating health professionals about disability: A review of interventions. Health and Social Care Education, 2(2), 20-37. 
37. SCHIAVENATO, M., 2009. Re-evaluating simulation in nursing education: beyond the human patient simulator. J Nurs Educ, 48(7), pp. 388-394.

38. SCHIFFMAN, S.S. AND ZERVAKIS, J., 2002. Taste and smell perception in the elderly: effect of medications and disease. Advances in food and nutrition research, 44, pp.247-346.

39. SCHIFFMAN, S.S., 2007. Critical illness and changes in sensory perception. Proceedings of the Nutrition Society, 66(3), pp.331-345.

40. SINCLAIR, B. and FERGUSON, K., 2009. Integrating Simulated Teaching/Learning Strategies in Undergraduate Nursing Education. International Journal of Nursing Education Scholarship, 6(1), pp. 1-11.

41. STIRLING, K., SMITH, G. and HOGG, G., 2012. The benefits of a ward simulation exercise as a learning experience. British Journal of Nursing, 21(2).

42. TANNER, C.A., 2006. Thinking like a nurse: A research-based model of clinical judgment in nursing Journal of Nursing Education, 45, pp. 204-221.

43. WILFORD, A. and DOYLE, T.J., 2006. Product focus. Integrating simulation training into the nursing curriculum. British Journal of Nursing, 15(17), pp. 926.

44. WORLD HEALTH ORGANISATION., 2015a-last update, Deafness and hearing loss factsheet [accessed ] [Homepage of World Health Organisation], [Online]. Available: http://www.who.int/mediacentre/ factsheets/fs300/en/ [14 September, 2015].

45. WORLD HEALTH ORGANISATION. 2015b. World Report on Ageing and Health. Luxembourg: World Health Organisation.

46. WORLD HEALTH ORGANISATION, PREVENTION OF BLINDNESS AND VISUAL IMPAIRMENT [Online]. Available: http://www.who.int/blindness/causes/priority/en/ [September 2017].

47. YEUN, E.J., BANG, H.Y., RYOO, E.N. and HA, E., 2014. Attitudes toward simulation-based learning in nursing students: An application of Q methodology. Nurse Education Today, 34(7), pp. 1062-1068. 